\title{
Determinants of exclusive breastfeeding practice for the first six months in mothers with infants between 6 and 15 months of age in Erbil city, Iraq: A cross-sectional study
}

Received: 11/ 4/ 2019

Accepted: $15 / 7 / 2019$

\begin{tabular}{c}
\hline Nabaz Sadraddin Sdeeq ${ }^{1 *} \quad$ Abubakir Majeed Saleh $^{2}$ \\
\hline Abstract
\end{tabular}

Background and objective: Breastfeeding is a useful and natural source of nutrition that provides the healthiest start for an infant. Despite its nutritional benefits, breastfeeding promotes a unique and emotional connection between mother and baby. This study aimed to assess the determinants of exclusive breastfeeding within the first six months of age in Erbil City, Iraq.

Methods: A cross-sectional study was conducted in Erbil city, Iraq, from December 2017 to December 2018. A convenience sampling method was used for selecting mothers of infants aged 6-15 months. A structured interviewer administered questionnaire was used for data collection. The statistical package for the social sciences was used for data analysis and a $P$ value of $\leq 0.05$ was regarded as statistically significant.

Results: A total of 306 mothers with children aged between 6 and 15 months were included. The prevalence of exclusive breastfeeding was $26.5 \%$. Around $36 \%$ of mothers had a primary school qualification, of whom $28.2 \%$ gave exclusive breastfeeding. Around $84 \%$ of the mother were housewives, of whom $28.3 \%$ had exclusive breastfeeding. Around $92 \%$ of the mothers had a birth at health facilities, of whom $26.2 \%$ gave exclusive breastfeeding. Around $50 \%$ of mothers had cesarean section deliveries, of whom $23.4 \%$ gave exclusive breastfeeding. Around $44 \%$ of the mothers mentioned that insufficient milk is the barrier to exclusive breastfeeding.

Conclusion: Exclusive breastfeeding still remains low compared to the current WHO recommendations. The most common barrier to continuing exclusive breastfeeding was the perception of insufficient milk production. Housewife mothers are more likely to breastfeed their infants exclusively, and least when the mother is a non-house wife.

Keywords: Exclusive breastfeeding; Mothers; Infants; Erbil.

\section{Introduction}

Optimal breastfeeding is the best source of nutrition for the newborn and the cornerstone for establishing healthy growth and development for children. Optimal breastfeeding is beneficial to the infant, the mother, the household, and the community. Optimally breastfed babies are less likely to develop childhood infections. ${ }^{1}$ Exclusive breastfeeding is defined as no other food or drink, not even water, except breast milk (including milk expressed or from a wet nurse) for six months of life. However, it allows the infant to receive ORS, drops, and syrups (vitamins, minerals, and medicines). Non-exclusive breastfeeding means breast milk along with infant formula, baby food, and even water within the first six months. ${ }^{2}$ On the other hand, suboptimal and inadequate breastfeeding practices frequently result in child malnutrition, which is a major cause of more than half of all child deaths. Exclusive breastfeeding is regarded as imperative for infants' survival. ${ }^{3}$ World Health Organization (WHO) and United Nations International Children's Fund (UNICEF) recommend mothers to initiate breastfeeding within the first hour after birth. Thereafter, mothers should continue

${ }^{1}$ Kurdistan Board for Medical Specialties, Erbil, I raq.

2 Department of Community Medicine, College of Medicine, Hawler Medical University, Erbil, I raq.

* Correspondence: nabazsadraddin@gmail.com 
feeding their babies with breast milk alone (including expressed milk or from a wet nurse) for at least the first six months of life before adding complementary feeding. Exclusively breastfed infants can only take oral rehydration solution, vitamins and minerals, and prescribed medications. Scientific studies by WHO and UNICEF have proven that breastfeeding is beneficial to both the child and the mother. ${ }^{4}$ Breast milk lowers the baby's risk of sickness from acute and chronic infections and is a cost-effective intervention that reduces infant mortality and morbidity. ${ }^{5}$ Consequently, the WHO has recommended that exclusive breastfeeding for six months of life is essential to achieve optimal growth, development, and better health for infants. ${ }^{6}$ Despite the recommendations, national exclusive breastfeeding prevalence in many developing countries remained very low, ranging from $33 \%$ in 1995 to $39 \%$ in 2010 among infants aged 0 to five months. ${ }^{7}$ The practice of exclusive breastfeeding is suboptimal in many parts of Kurdistan Region to various extent. This study aimed to assess the determinants of exclusive breastfeeding within the first six months of age in Erbil City, Iraq.

\section{Methods}

Study design: A cross-sectional descriptive study.

Duration: The study was conducted from 1st of December 2017 to 1st of December 2018.

Setting: A study was carried out in three Primary health care centers (Muhammad Bajalan, Shadi, and Mnara) among 24 centers with an immunization unit in the center of Erbil city.

Sampling method: The three primary health care centers were selected using systematic sampling techniques. A convenience sampling was used to select mothers of infants aged between 6 and 15 months. Mothers with children of these ages were targeted so that they can recall their exclusive breastfeeding practice. The mothers normally come to the immunization unit with babies at six, nine, and fifteen months of age.

Sample size: All mothers of infants aged between 6 and 15 months who visited the immunization unit in the three selected primary health centers were included in the study. The total number of these mothers was 306 mother-child pairs.

Data collection: Data were collected from mothers of the infants in both immunization and the outpatient department in primary health care centers by using a structured interviewer administered questionnaire. The questionnaire included demographic variables such as a child's age and gender, mother's age, education, occupation, type of delivery, and type of feeding during the 1st six months, father's education, and the number of family members.

Statistical analysis: The statistical package for the social sciences (SPSS version 25) was used for data analysis. The Chi-square test was used to test the significance of associations between independent and dependent variables. A $P$ value of $\leq 0.05$ was regarded as statistically significant.

Ethical consideration: This study was approved by the Research Ethics Committee of the Kurdistan Board for Medical Specialties. Verbal informed consent was obtained from all participants after giving them all the required information.

\section{Results}

Eighty one $(26.47 \%)$ mothers were exclusively breastfeeding for six months, and $31(10.1 \%)$ mothers did not breastfeed since birth (Table1).

\section{Gender of infants}

There were slightly more male babies 160 $(52.3 \%)$ than female babies $146(47.7 \%)$ (Table 2).

Age, education level and occupation of mothers

The age range of mothers was 17 to 44 years. One hundred sixty $(52.3 \%)$ mothers were in the age group of $25-34$ years; 
47 of them (29.4\%) were exclusively breastfeeding their babies. Ninety mothers $(29.4 \%)$ were in the age group (17-24), only 17 of them $(18.9 \%)$ were exclusively breastfed their babies). One hundred ten $(35.9 \%)$ respondents had primary school qualifications, and 31 of them (28.2\%) exclusively breastfed their babies. Fortyseven $(15.4 \%)$ mothers were illiterate, and only $12(25.5 \%)$ of them were exclusively breastfeeding their babies. Two hundred fifty eight $(84.3 \%)$ mothers were housewives, $73(28.3 \%)$ of them gave exclusive breastfeeding to their babies. Mothers with all other occupations were 48 $(15.7 \%)$, only eight $(16.7 \%)$ of them gave exclusive breastfeeding to their babies (Table 3).

Table 1: Distribution of infants according to the type of feeding.

\begin{tabular}{llcc}
\hline & & Frequency & Percent \\
\hline Type of feeding & Exclusive breastfeeding & 81 & 26.5 \\
& Non-exclusive breastfeeding & 194 & 63.4 \\
& Non-breast feed & 31 & 10.1 \\
& Total & 306 & 100.0 \\
\hline
\end{tabular}

Table 2: Gender of infants.

\begin{tabular}{lcc}
\hline Gender & Frequency & Percent \\
\hline Male & 160 & 52.3 \\
Female & 146 & 47.7 \\
Total & 306 & 100.0 \\
\hline
\end{tabular}

Table 3: Association of age, qualification, and occupation characteristics of mothers with exclusive breastfeeding.

\begin{tabular}{|c|c|c|c|c|c|}
\hline Variable & $\begin{array}{c}\text { Non-exclusive } \\
\text { breastfeeding } \\
\text { No. (\%) }\end{array}$ & $\begin{array}{c}\begin{array}{c}\text { Exclusive } \\
\text { breastfeeding }\end{array} \\
\text { No. (\%) }\end{array}$ & $\begin{array}{c}\text { Total } \\
\text { No. (\%) }\end{array}$ & Percent* & $P$ value \\
\hline \multicolumn{6}{|l|}{ Age group mother } \\
\hline $17-24$ & $73(81.1 \%)$ & $17(18.9 \%)$ & $90(100 \%)$ & 29.4 & 0.151 \\
\hline $25-34$ & $113(70.6 \%)$ & $47(29.4 \%)$ & $160(100 \%)$ & 52.3 & \\
\hline $35-44$ & $39(69.6 \%)$ & $17(30.4 \%)$ & $56(100 \%)$ & 18.3 & \\
\hline \multicolumn{6}{|l|}{ Education level of mother } \\
\hline Illiterate & $35(74.5 \%)$ & $12(25.5 \%)$ & $47(100 \%)$ & 15.4 & 0.887 \\
\hline Primary & $79(71.8 \%)$ & $31(28.2 \%)$ & $110(100 \%)$ & 35.9 & \\
\hline Secondary & $49(72.1 \%)$ & $19(27.9 \%)$ & $68(100 \%)$ & 22.2 & \\
\hline College and postgraduate & $62(76.5 \%)$ & $19(23.5 \%)$ & $81(100 \%)$ & 26.5 & \\
\hline \multicolumn{6}{|l|}{ Occupation of mother } \\
\hline Non-house wife & $40(83.3 \%)$ & $8(16.7 \%)$ & $48(100.0 \%)$ & 15.7 & 0.094 \\
\hline Housewife & $185(71.7 \%)$ & $73(28.3 \%)$ & $258(100.0 \%)$ & 84.3 & \\
\hline Total & 225 (73.5\%) & $81(26.5 \%)$ & $306(100.0 \%)$ & 100.0 & \\
\hline
\end{tabular}

${ }^{*}$ Calculated as a column percentage. 
https:/ / doi.org/ 10.15218/ zjms.2021.001

Barriers to exclusive breastfeeding among mothers

Ninety-eight (43.57\%) respondents said that the primary challenge that hinders exclusive breastfeeding practice was insufficient milk and 47 (20.89\%) respondents mentioned child's refusal. Other causes were working, a problem in the breast, mothers' dislike, pregnancy, and others $(7.1 \%, 8.0 \%, 7.1 \%, 0.4 \%$, and $12.89 \%$ ) respectively (Table 4 ).

Factors associated with exclusive breastfeeding

One hundred sixty five (53.92\%) nursing mothers were living in low socioeconomic status; only $46(27.9 \%)$ of them gave their babies exclusive breastfeeding. Seven mothers $(2.29 \%)$ had high socioeconomic status; only two of them gave their babies exclusive breastfeeding. One hundred ninety three $(63.07 \%)$ mothers were living in a family with five members or less; $50(25.9 \%)$ of them gave their babies exclusive breastfeeding. The remaining 130 mothers $(36.92 \%)$ were living in a family with more than five; $31(27.4 \%)$ of them gave exclusive breastfeeding to their babies. One hundred fifty two $(49.67 \%)$ mothers had vaginal deliveries; only 45 $(29.6 \%)$ of them gave their babies breastfeeding exclusively. One hundred fifty four $(50.33 \%)$ mothers had cesarean section deliveries, and $36(23.4 \%)$ of them gave breast milk exclusively. One hundred five $(34.31 \%)$ mothers had a first child; $17(16.2 \%)$ of them gave their babies exclusive breastfeeding. While 167 $(54.58 \%)$ mothers had two to four children, only $52(31.1 \%)$ of them gave their babies exclusive breastfeeding. Twenty seven $(8.82 \%)$ mothers' births were at home; eight(29.6\%) of them gave their children exclusive breastfeeding. Mothers giving birth in a health facility were $279(91.18 \%)$; only $73(26.2 \%)$ of them gave their infants exclusive breastfeeding (Table 5).

Table 4: Barriers to exclusive breastfeeding among mothers.

\begin{tabular}{lcc}
\hline & Frequency & Percent \\
\hline Working & 16 & 7.1 \\
Insufficient milk & 98 & 43.57 \\
A problem in the breast & 18 & 8.0 \\
Child refused & 47 & 20.89 \\
Mother dislike & 16 & 7.1 \\
Pregnancy & 1 & 0.4 \\
Others & 29 & 12.89 \\
Total & 225 & 100.0
\end{tabular}


Determinants of exclusive breastfeeding practice....

Zanco J. Med. Sci., Vol. 25, No. (1), April, 2021 https:// doi.org/ 10.15218/ zjms.2021.001

Table 5: Association of socioeconomic status, family member and mode of delivery of mothers with exclusive breastfeeding

\begin{tabular}{lccccc}
\hline Variable & $\begin{array}{c}\text { Non- } \\
\text { exclusive } \\
\text { breastfeeding } \\
\text { No. (\%) }\end{array}$ & $\begin{array}{c}\text { Exclusive } \\
\text { breastfeeding }\end{array}$ & Total & Percent $^{*}$ & $P$ value \\
& No. (\%) & No. (\%) & & \\
\hline Socioeconomic status & $119(72.1 \%)$ & $46(27.9 \%)$ & $165(100.0 \%)$ & 53.92 & 0.811 \\
Low & $101(75.4 \%)$ & $33(24.6 \%)$ & $134(100.0 \%)$ & 43.79 & \\
Moderate & $5(71.4 \%)$ & $2(28.6 \%)$ & $7(100.0 \%)$ & 2.29 & \\
High & & & & &
\end{tabular}

Family member

$\begin{array}{lccccc}1-5 & 143(74.1 \%) & 50(25.9 \%) & 193(100.0 \%) & 63.07 & 0.770 \\ >5 & 82(72.6 \%) & 31(27.4 \%) & 113(100.0 \%) & 36.92 & \\ \text { Mode of delivery } & & & & & \\ \text { Normal vaginal delivery } & 107(70.4 \%) & 45(29.6 \%) & 152(100.0 \%) & 49.67 & 0.217 \\ \text { Cesarean section } & 118(76.6 \%) & 36(23.4 \%) & 154(100.0 \%) & 50.33 & \end{array}$

Birth order of child

First child $88(83.8 \%) \quad 17(16.2 \%) \quad 105(100.0 \%) \quad 34.31 \quad 0.012$

Second-fourth child

$115(68.9 \%)$

$52(31.1 \%)$

$167(100.0 \%)$

54.58

Fifth and more

$22(64.7 \%)$

$12(35.3 \%)$

$34(100.0 \%)$

11.11

Delivery place

Home

$8(29.6 \%)$

$27(100.0 \%)$

8.82

0.697

Health facility

$206(73.8 \%)$

$73(26.2 \%)$

$279(100.0 \%)$

91.18

Total

225 (73.5\%)

$81(26.5 \%)$

306 (100.0\%)

100.0

${ }^{*}$ Calculated as a column percentage. 


\section{Discussion}

The prevalence of exclusive breastfeeding in this study was $(26.47 \%)$. This finding is closer to the finding of studies done in Saudi Arabia $^{8}$ and the United Arab Emirates $^{9}$ in which they reported $27.3 \%$ and $25 \%$ and higher than the finding of another study done in Bhaktapur in Nepalin which only $9 \%$ of the children were exclusively breastfed at six months of age. ${ }^{10}$ In this study, $194(63.4 \%)$ mothers reported mixed feeding. Many researchers from Arab countries also reported mixed feeding as a common feeding practice ${ }^{11-14}$ and $10.1 \%$ of mothers never breastfeed their infants. This rate close with the finding of a study done in Egypt, ${ }^{14}$ which reported $7.1 \%$ of the infants were only bottle-fed. In our study, 98 (43.57\%) mothers said that the primary challenge that hinders exclusive breastfeeding practice was insufficient milk. This similar to the findings of other studies done in Saudi Arabia, ${ }^{15}$ Lebanon ${ }^{16}$ and the United States of America. ${ }^{17,18}$ Another reason that the mothers mentioned for discontinuing breastfeeding was infants refused to breastfeed (20.89\%). Many other studies from Saudi Arabia ${ }^{19}$ and Brazil $^{20}$ reported that the child had weaned itself. Other reasons for not giving exclusive breastfeeding to their infants include pregnancy, hunger, or crying after the feeding; this is similar to the finding of other studies done in Saudi Arabia, ${ }^{15}$ Lebanon, ${ }^{16}$ and Jordan. ${ }^{21}$ This study shows that older mothers are more likely to have good exclusive breastfeeding practice than younger ones, but the difference was not statistically significant $(P=0.151)$. This finding is similar to the results of studies done in Nigeria, which reported no significant influence of mother's age and the practice of exclusive or non-exclusive breastfeeding. ${ }^{22,23}$ While significant relation reported in other studies carried out in Canada and the United States of America were older women (25 years older) are more likely to initiate and continue breastfeeding compared to younger women. ${ }^{24,25}$ In this study, there was a relationship between the mother's level of education and the practice of exclusive $(P=0.881)$. These results imply that increasing the level of education does not affect compliance to exclusive breastfeeding. This finding similar to the studies done in Nigeria and Spain in which no significant influence of mother's level of education and the practice of exclusive or non-exclusive breastfeeding were reported. ${ }^{22,23}$ But a study from the United States of America reported that higher education in women in developing countries was associated with a shorter duration of exclusive breastfeeding. ${ }^{26}$ Other studies done in Nigeria also found the mothers level of education to be positively correlated with the act of exclusive breastfeeding. ${ }^{27,28}$ In this study, exclusive breastfeeding was highest among housewives $(28.2 \%)$. On the other hand, $16.6 \%$ of non-housewife mothers practiced exclusively breastfeeding. However, there was no significant association between them $(P=0.094)$. This study is consistent with other studies done in India and the United States of America, which reported no effect of maternal work on exclusive breastfeeding. ${ }^{29}$ However, this study is not compatible with many studies done in Jordan, ${ }^{13}$ Saudi Arabia, ${ }^{30}$ Malaysia, ${ }^{31}$ and Canada $^{32}$ in different cultures that reported the maternal employment has a negative impact on exclusive breastfeeding. A study from Australia ${ }^{33}$ also indicated that working mothers who returned to work were less likely to continue breastfeeding. In this study, we found that cesarean section adversely affects the adoption of exclusive breastfeeding compared to spontaneous vaginal delivery, but the difference was not statistically significant $(P=0.217)$. This study conforms with studies done in the United Kingdom, which stated that there was no association. ${ }^{34,35}$ differs with studies reported the adverse effect of cesarean section on exclusive breastfeeding. $^{36,37}$ In this study, young mothers with one child breastfed for 
shorter periods than did older multiparous mothers $(P=0.012)$. Similar results were reported in many other countries such as the Netherlands, ${ }^{38}$ Australia, ${ }^{39}$ Denmark, ${ }^{40}$ and United Kingdom. ${ }^{41}$ This study found that there is no statistically significant difference between mothers who had a birth at a government health facility compared to mothers who had a birth at home $(P=0.697)$. Other studies reported different findings. In a study from Nepal, mothers who deliver at home were more likely to practice exclusive breastfeeding. ${ }^{42}$ Another study done in Ghana reported that delivery at a hospital/ polyclinic was associated with a two times higher likelihood of exclusive breastfeeding. ${ }^{43}$ Dongre et al. (2010) in a study done in India, stated that the better practices related to early initiation, frequency of feeding, and exclusive breastfeeding in the study area might be attributed to the high proportion of hospital deliveries. ${ }^{44}$ This study reveals that socioeconomic status had no relation to the practice of exclusive breastfeeding $(P=0.811)$. It differs from the finding of the studies of Wright et al. (2004) and Rojjanasrirat and Sousa, (2010) which stated that low socioeconomic status results in early weaning. ${ }^{45}$ Aidam et al. (2005) also reported that high socioeconomic status was an enabling factor for exclusive breastfeeding in Ghana. ${ }^{43}$ In this study, there was no significant relationship between family members and the practice of exclusive and non-exclusive breastfeeding $(P=0.770)$. These findings were not in line with studies conducted by Brand et al., ${ }^{46}$ Bevan and Brown, ${ }^{47}$ and Demirtas, ${ }^{48}$ as they reported that the presence of partners and families play a significant role in helping and supporting mothers to continue exclusive breastfeeding for six months, thereby significantly decreasing the risk of early discontinuation of exclusive breastfeeding.

\section{Conclusion}

Exclusive breastfeeding remains still low compared to the current WHO recommendations; suboptimal exclusive breastfeeding practices were related to many factors. The most common barrier to not continue exclusive breastfeeding was the perception of insufficient milk production. Housewife mothers are more likely to exclusively breastfeed their infants, and least when the mother is nonhousewife.

\section{Competing interests}

The authors declare no competing interests.

\section{References}

1. Ahmed KY, Page A, Arota A, Ogbo F A. Trends and determinants of early initiation of breastfeeding and exclusive breastfeeding in Ethiopia from 2000 to 2016. Int Breastfeeding J 2019; 14:40.

2. World Health Organization. Indicators for assessing infant and young child feeding practices Part 1 Definitions; 2008. (Accessed March 18, 2021, at: http://apps.who.int/iris/ bitstream/10665/43895/1/9789241596664 eng.pdf).

3. $\bar{M}$ a JQ, Zhou LL, Hu YQ, Liu JR, Liu SS, Zhang Jet al. A summary index of infant and child feeding practices is associated with child growth in urban Shanghai. BMC Public Health 2012; 12:568.

4. Black RE, Victoria CG, Walker SP, Christian P, De Onis M, Ezzati M. Maternal and child undernutrition and overweight in low-income and middle-income countries. Lancet 2013; 382(9890):427-51.

5. Mundagowa $\mathrm{P}$ T, Chadambuka EM, Chimberengwa PT, Mutseyekwa FM. Determinants of exclusive breastfeeding among mothers of infants aged 6-12 months in Gwanda district, Zimbabwe. Int Breastfeeding J 2019; $14: 30$.

6. Cai X, Wardlaw T, Brwon D. W. Global trends in exclusive breastfeeding. Int Breastfeed J 2012; 7:12.

7. Ogbeide DO, Siddiqui S, Al-Khalifa IM, Karim A. Breastfeeding in a Saudi Arabian Community: Profile of parents and influencing factors. Saudi Med J 2004; 25(5):580-4.

8. Radwan $H$. Patterns and determinants of breastfeeding and complementary feeding practices of Emirati mothers in the United Arab Emirates. BMC Public Health 2013; 13:171.

9. Ulak M, Chandyo RK, Mellander LL, Shresta PS, Strand TA. Infant feeding practices in Bhaktapur, Nepal: A cross-sectional, health facility-based survey. Int Breastfeed J 2012; 7:1. 
10. Alwelaie YA, Alsuhaibani EA, Al-Harthy AM, Radwan RH, Al-Mohammady RG, Almutairi AM. Breastfeeding knowledge and attitude among Saudi women in Central Saudi Arabia. Saudi Med J 2010; 31(2):193-8.

11. Dashti M, Scott JA, Edwards CA, Al-Sughayer M. Determinants of breastfeeding initiation among mothers in Kuwait. Int Breastfeed J 2010; 5:7.

12. Khassawneh M, Khader $Y$, AmarinZ, Alkafajei A. Knowledge, attitude and practice of breastfeeding in the north of Jordan: a cross-sectional study. Int Breastfeed J 2006; 1:17.

13. El-Gilany $\mathrm{AH}$. Breastfeeding indicators in Dakahlia Governorate. East Mediterr Health J 2003; 9(5-6):961-73.

14. El Mouzan M. I. Trends in infant nutrition in Saudi Arabia: compliance with WHO recommendations. Ann Saudi Med 2009; 29(1):20-3.

15. Nabulsi M. Why are breastfeeding rates low in Lebanon? A qualitative study. BMC Pediatr 2011; $11: 75$.

16. Ware JL, Webb L, Levy M. Barriers to breastfeeding in the African American population of Shelby County, Tennessee. Breastfeed Med 2014; 9(8):385-92.

17. Wood NK, Woods NF, Blackburn ST, Sanders EA. Interventions that Enhance Breastfeeding Initiation, Duration, and Exclusivity: A Systematic Review. MCN Am J Matern Child Nurs 2016; 41(5):299-307.

18. Fida NM, Al-Aama JY. Pattern of infant feeding at a university hospital in western Saudi Arabia. Saudi Med J 2003; 24(7):725-9.

19. Wayland C. Breastfeeding patterns in Rio Branco, Acre, Brazil: a survey of reasons for weaning. Cad Saude Publica 2004; 20(6):175761.

20. Oweis A, Tayem A, Froelicher ES. Breastfeeding practices among Jordanian women. Int J Nurs Pract 2009; 15(1):32-40.

21. Ogunlesi TA. Maternal socio-demographic factors influencing the initiation and exclusivity of breastfeeding in a Nigerian semi-urbansetting. Matern Child Health J 2010;14(3):459-65.

22. Oche MO, Umar AS, Ahmed H. Knowledge and practice of exclusive breastfeeding in Kwara State. Afr Health Sci J 2011; 11(3):518-23.

23. Dennis CL. Breastfeeding initiation and duration: A 1990-2000 Literature Review. J Obstet Gynecol Neonatal Nurs 2002b; 31(1):12-32.

24. Erteml O, Votto N, Leventhal JM. The timing and predictors of the early termination of breastfeeding. Pediatrics 2001; 107(3):5438.

25. Colodro-Conde L, Sanchez-Romera JF, Tornero-Gomez MJ, Perez-Riquelme $F$, Polo-Tomas M, Ordinana JR. Relationship between level of education and breastfeeding duration depends on social context: Breastfeeding trends over 40 years in Spain. J Hum Lact 2011; (3):272-8.
26. Jones JR, Kogan MD, Simgh GK, Dee DL, Grummer-Strawn LM. Factors associated with exclusive breastfeeding in United States. Pediatrics 2011; 128(6):1117-25.

27. Sobo RA, Sokoya GO, Awonusi PA, Odufuwa BA. Knowledge, attitudes and practice of exclusive breastfeeding among rural mothers Inljebu-Ode. Journal of Nursing 2008; 19:121-4.

28. Mundi R. Analysis of factors influencing the practice of exclusive breastfeeding in Nigeria's federal capital territory. Journal of Zaria Geographer 2008; 17(1):1-11

29. Petrova A, Ayers C, Stechna S. Effectiveness of exclusive breastfeeding promotion in lowincome mothers: A randomized controlled study. Breastfeed Med 2009; 4:63-9.

30. El-Gilany A, El-Wehady A. Maternal work and infant health in Al-Hassa, Saudi Arabia. Paediatrs 2007; 12(4):100-5.

31. Tan KL. Factors associated with non-exclusive breastfeeding among 4-week post-partum mothers in Klang District, Peninsular Malaysia. Mal J Nutr 2009; 15:11-8.

32. Al-Sahab B, Lanes A, Feldman M. Prevalence and predictors of 6-months exclusive breastfeeding among Canadian women: A national survey. BMC Pediatr 2010; 10:20.

33. Dagher RK, McGovern PM, Schold JD, Randall XJ. Determinants of breastfeeding initiation and cessation among employed mothers: a prospective cohort study. BMC Pregnancy and Childbirth 2016; 16:194.

34. Agboado G, Michel E, Jackson E. Factors associated with breastfeeding cessation in nursing mothers in a peer support programme in Eastern Lancashire. BMC Pediatr 2010; 10:3.

35. Patel RR, Liebling RE, Murphy DJ. Effect of operative delivery in the second stage of labor on breastfeeding success. Birth 2003; 30:255-60.

36. Qiu L, Zhao $Y$, Binns $C W$, Lee $A H$, Xie $X$. Initiation of breastfeeding and prevalence of exclusive breastfeeding at hospital discharge in urban, suburban and rural areas of Zhejiang China. Int Breastfeed J 2009; 4:1.

37. Islam Z, Fallah R, Golestan M. Relationship between delivery type and successful breastfeeding. Iran J Pediatr 2008; 18(Suppl 1):37-52.

38. Bulk-Bunschoten AMW, Bodegon SV, Reerink JD, Jong PCM, Groot CJ. Reluctance to continue breastfeeding in the Netherlands. Acta Paediatrica 2001; 90:1047-53.

39. Forster D, McLachlan HL, Lumley J. Factors associated with breastfeeding at six months postpartum in a group of Australian women. Int Breastfeed J 2006; 18:1-12.

40. Kronborg $\mathrm{H}$, Vaeth $\mathrm{M}$. The influence of psychosocial factors on the duration of breastfeeding. Scand J Public Health 2004; 32(3):210-18.

41. Trussel J, Grummer-Strawn L, Rodriguez G, 
Vanlandingham M. Trends and differentials in
breastfeeding behaviour: Evidence from the WFS and DHS. Population Studies 1992; 46:285-307.

42. Khanal V, Sauer K, Zhoa Y. Exclusive breastfeeding practices in relation to social and health determinants: a comparison of the 2006 and 2011 Nepal Demographic and Health Surveys. BMC Public Health 2013; 13:958.

43. Aidam BA, Pérez-Escamilla R, Lartey A, Aidam J. Factors associated with exclusive breastfeeding in Accra, Ghana. Eur J Clin Nutr 2005; 59(6):789-96.

44. Dongre AR, Deshmukh PR, Rawool AP, Garg BS. Where and how breastfeeding promotion initiatives should focus its attention? A study from rural Wardha. Indian J Community Med 2010; 35(2):226-9.

45. Rojjanasrirat W, Sousa V. Perceptions of breastfeeding and planned a return to work or school among low-income pregnant women in the USA. J Clin Nurs 2010; 19(13-14):2014-22.

46. Brand E, Kothari C, Stark, M. Factors related to breastfeeding discontinuation between hospital discharge and two weeks postpartum. J Perinat Educ 2011; 20(1):36-44.

47. Bevan G, Brown M. Interventions in exclusive breastfeeding: A systematic review. $\mathrm{Br} J$ Nurs 2014; 23(2):86-9.

48. Demirtas B. Strategies to support breastfeeding: A review. Int Nurs Rev 2012; 59(4):474-81. 